\title{
Induction of Mitotic Catastrophe in Human Cervical Cancer Cells After Administration of Aloe-emodin
}

\author{
WOJCIECH TRYBUS ${ }^{1}$, TEODORA KRÓL ${ }^{1}$, EWA TRYBUS ${ }^{1}$, ANNA STACHURSKA ${ }^{2}$, \\ ANNA KOPACZ-BEDNARSKA ${ }^{1}$ and GRZEGORZ KRÓL ${ }^{3}$ \\ ${ }^{1}$ Department of Cell Biology and Electron Microscopy, Institute of Biology, \\ The Jan Kochanowski University, Kielce, Poland; \\ ${ }^{2}$ Department of Immunohaematology, Centre of Postgraduate Medical Education, Warsaw, Poland; \\ ${ }^{3}$ Faculty of Management, University of Warsaw, Warsaw, Poland
}

\begin{abstract}
Background: Aloe-emodin is an anthraquinone with potential pharmacological properties, including numerous antitumor properties. The purpose of the study was to determine whether aloe-emodin induces mitotic death in cervical cancer cells. Materials and Methods: Analysis of morphological changes as surrogate mitotic death indicators in HeLa cells was carried out using optical, fluorescence and electron microscopy. Viability was determined by 3-(4,5-dimethylthiazol-2-yl)-2-5diphenyltetrazolium bromide reduction assay. Cell-cycle analysis was performed using flow cytometry. Results: Aloeemodin increased the number of multinucleate cells, giant and micronuclear cells. There was a concentration-dependent decrease in the mitotic index with a predominance of cells in the metaphase of the mitotic process and inhibition of division in the $G_{2} / M$ phase of the cell cycle. The presence of cells with abnormal mitosis and cells with injury to the division spindle was also demonstrated. Conclusion: Aloe-emodin induces mitotic catastrophe in cervical cancer cells.
\end{abstract}

For many years, apoptosis has been recognized as the main type of cell death. Recent studies have shown that treatment of cancer apoptosis induced by chemotherapy drugs (including plant origin) in addition to programmed cell death, may induce alternative types of death in cancer cells, including mitotic catastrophe $(1,2)$. Compounds inducing mitotic catastrophe in HeLa cells is the subject of our research.

Aloe-emodin (1,8-dihydroxy-3-hydroxymethyl-9,10anthrachinone) is on anthraquinone found in the leaves and

Correspondence to: Wojciech Trybus, Department of Cell Biology and Electron Microscopy, Institute of Biology, The Jan Kochanowski University, Świętokrzyska 15, 25-406 Kielce, Poland. wojciech.trybus@ujk.edu.pl

Key Words: Anthraquinones, aloe-emodin, mitotic death, cell cycle, apoptosis. roots of Rheum palmatum L. (3), Rhamnus frangula L., Rhamnus cathartica L. (4), Aloe barbadensis Mill., and Aloe arborescens Mill. (5). Numerous studies indicate that aloeemodin is a compound with multiple biological activities, and its antitumor mechanism of action is based on proapoptotic and antiproliferative properties, and has still not been fully elucidated $(6,7)$.

The aim of the study was to evaluate the effect of aloeemodin on morphological and biochemical changes in cervical cancer cells with particular attention to changes that could indicate cell death alternative to apoptosis, i.e. mitotic catastrophe.

\section{Materials and Methods}

In vitro culture conditions. HeLa cells were cultured in dishes (Nunc) at $37^{\circ} \mathrm{C}$ and with $5 \%$ carbon dioxide in a DirectHeat $\mathrm{CO}_{2}$ incubator (Thermo Fisher Scientific, Waltham, MA, USA). The culture was carried out on Dulbecco's modified Eagle's medium (DMEM) supplemented with $10 \%$ fetal bovine serum (FBS), with the addition of $1 \%$ of a mixture of antibiotics containing penicillin, streptomycin and amphotericin B. Reagents were from Thermo Fisher Scientific. Aloe-emodin $\left(\mathrm{C}_{15} \mathrm{H}_{10} \mathrm{O}_{5}\right)$ was purchased from Sigma-Aldrich (St. Louis, MO, USA). The cells were exposed to aloe-emodin at concentrations of $1,15,30,60$ and $100 \mu \mathrm{M}$ for 24 and $48 \mathrm{~h}$.

Preparation of cells for morphological analysis. The cells (control and test) were grown on sterile cover slides in culture dishes. After 24 and 48 hours of exposure to aloe-emodin, the cells were fixed in methanol, stained with Harris hematoxylin (Sigma-Aldrich) followed by eosin solution (Sigma-Aldrich). The preparations were dehydrated with increasing series of alcohol, cleared in xylene and immersed in Histokitt (Glaswarenfabrik Karl Hecht GmbH \& Co $\mathrm{KG}$, Germany). The experiment was performed in three independent experiments (three repetitions for individual concentrations and incubation times, including the control group).

Evaluation of cell mitotic index and morphological changes. Analysis of control cells and cells treated with aloe-emodin was performed using the Nikon Eclipse 80i light microscope with Nikon Instruments 
NIS Elements D 3.10 (Nikon Instruments, Amsterdam, the Netherlands). In each of the preparations 5,000 cells were counted in three independent experiments (15,000 cells/concentration/time).

Based on the obtained results, the mitotic index and the number of cells with morphological changes defining mitotic death were determined, including the presence of giant cells, multinucleated cells, cells containing micronuclei in cytoplasm, and the presence of cells inhibited in metaphase $(8,9)$. Cell analysis for micronuclei was performed based on the morphological characteristics reported by Fenech et al. (10). In addition, the number of apoptotic cells was determined.

Analysis of the cell cycle. The effect of aloe-emodin on cell distribution in the cell cycle was assessed by flow cytometry. The cells were incubated with aloe-emodin for $48 \mathrm{~h}$ at a concentration of $1 \mu \mathrm{M}$ and $100 \mu \mathrm{M}$. After detaching the cells with trypsin, they were fixed with ice-cold $70 \%$ ethanol. The cells were rinsed in phosphatebuffered saline and then labeled with a suspension containing $0.1 \%$ NP-40, $10 \mu \mathrm{g} / \mathrm{ml}$ of DNAase-free RNAse and $5 \mu \mathrm{g}$ of propidium iodide. After $15 \mathrm{~min}$ of incubation, the cells were analyzed using FACSCanto II and the FACSDiva program (BD Biosciences, San Jose, CA, USA). A total of 10,000 events were analyzed in each sample. The percentage of cells in individual phases of the cycle was estimated using the ModFit LT 4.1.7 program (Verity Software House, Topsham ME, USA).

Evaluation of ultrastructural changes. After 48 hours' incubation, cells for transmission electron microscopy were prepared according to the modified method of Marzella and Glauman (11). Cells were fixed in $3 \%$ glutaraldehyde and $2 \%$ osmium tetroxide (SPI Supplies, West Chester, PA, USA), and embedded in Epon 812 resin (Serva Electrophoresis, Heidelberg, Germany). Specimen for the TECNAI G2 Spirit microscope (FEI Company, Hillsboro, OR, USA) were prepared using EM UC7 ultramicrotome (Leica Microsystems, Wetzlar, Germany).

Labeling of cell nuclei with fluorochrome 4',6-diamidine-2phenylindole (DAPI). After 48 hours of incubation of the cells in the basal medium (control cells) and medium with aloe-emodin at $100 \mu \mathrm{M}$ (test cells), staining was performed with $10 \mu \mathrm{g} / \mathrm{ml}$ DAPI solution (Sigma Aldrich). The prepared preparations were analyzed using a Nikon TiE fluorescence microscope (Nikon Instruments) using a DAPI dichroic filter block (358 nm excitation, emission above $461 \mathrm{~nm}$ ).

Cell viability assay 3-(4,5-dimethylthiazol-2-yl)-2-5-diphenyltetrazole bromide (MTT) reduction assay. Cells plated on 96-well plates (Nunc) were incubated at $37^{\circ} \mathrm{C}$ for 48 hours in a medium containing aloe-emodin at concentrations of $1-100 \mu \mathrm{M}$. The medium was then removed and the cells were incubated for $2 \mathrm{~h}$ with a solution of MTT (Sigma-Aldrich) according to the modified Mossmann method (12). After removing the medium from MTT, precipitate (containing formazan crystals) was dissolved in DMSO and shaken for a period of $10 \mathrm{~min}$. The absorbance was read on a Synergy 2 multimode microplate reader (BioTek, Winooski, VT, USA) at a wavelength of $570 \mathrm{~nm}$ and $690 \mathrm{~nm}$. The experiment was performed in three independent experiments.

Statistical analysis. The significance of the obtained differences was determined using statistical analysis, carried out using Statistica 10.0 software (StatSoft, Krakow, Poland). The results obtained were evaluated using a non-parametric Chi-squared test. The cell viability analysis was supported by the Tukey's test and the cell-cycle distribution by Newman-Keul's test. The differences were statistically confirmed at $p<0.05$.

\section{Results}

Aloe-emodin inhibits cell division. Exposure of HeLa cells to increasing aloe-emodin concentration for 24 and 48 hours caused a highly statistically significant reduction in the mitotic index. The highest inhibition of division, to $3.50 \%$ (Figure 1), was demonstrated after 48-hour activity of aloeemodin at $100 \mu \mathrm{M}$. It should be emphasized that cells in the metaphase stage (Figure 2) comprised $85.25 \%$ (24-hour incubation) and $88.68 \%$ (48-hour incubation) of the dividing cells.

From measurements made using flow cytometry, it appears that aloe-emodin induces cell-cycle arrest in $\mathrm{HeLa}$ cells (Figure 3). The most significant $\left(\mathrm{F}_{(2,6)}=239,09\right.$, $\left.p<0.001, \eta^{2}=0.988\right)$ increase in the percentage of cells was $60.78 \%$ in the $\mathrm{G}_{2} / \mathrm{M}$ phase as a result of treating cells with $100 \mu \mathrm{M}$ aloe-emodin compared with $14.18 \%$ cells in the $\mathrm{G}_{2} / \mathrm{M}$ phase after aloe-emodin at a concentration of $1 \mu \mathrm{M}$ and control (6.47\%). At the same time, with $100 \mu \mathrm{M}$ aloeemodin, a reduction in cells in the $\mathrm{G}_{0} / \mathrm{G}_{1}$ phase to $26.33 \%$ $\left(\mathrm{F}_{(2,6)}=279,084, p<0.001, \eta^{2}=0.989\right)$ was demonstrated. Control cells in this phase accounted for $75.22 \%$. The results indicate that the encumbrance of HeLa cells with aloeemodin results in a concentration-dependent significant increase in the cell population in the $G_{2} / M$ phase.

Aloe-emodin induces abnormalities of mitosis and mitotic death. With respect to control values, treatment with aloeemodin led to a highly statistically significant increase in the number of multinucleated cells, cells with micronuclei located near the nucleus and giant cells was demonstrated (Figure 4). Giant cells in the interphase stage contained several nuclei varying in size and shape, often with one or more micronuclei (Figure 5B and 6E). Cells with abnormal chromosomal segregation at various stages of mitotic division, with the chromosomes remaining in the cytoplasm, not pulled to the poles of the cell were also found (Figure 5D and 6C). The presence of cells with abnormal metaphase (bipolar, tripolar, and multipolar) was also characteristic of treatment with aloe-emodin (Figure 6B). The dispersal of the Golgi apparatus in the form of numerous vesicles in the cytoplasm was also observed in the cells (Figure 5C).

Aloe-emodin reduces viability and induces apoptosis of HeLa cells. After culture of cells for 48 hours in a medium supplemented with different concentrations of aloe-emodin, a highly statistically significant reduction in cell viability was observed (Figure 7B). The half-maximal inhibitory 


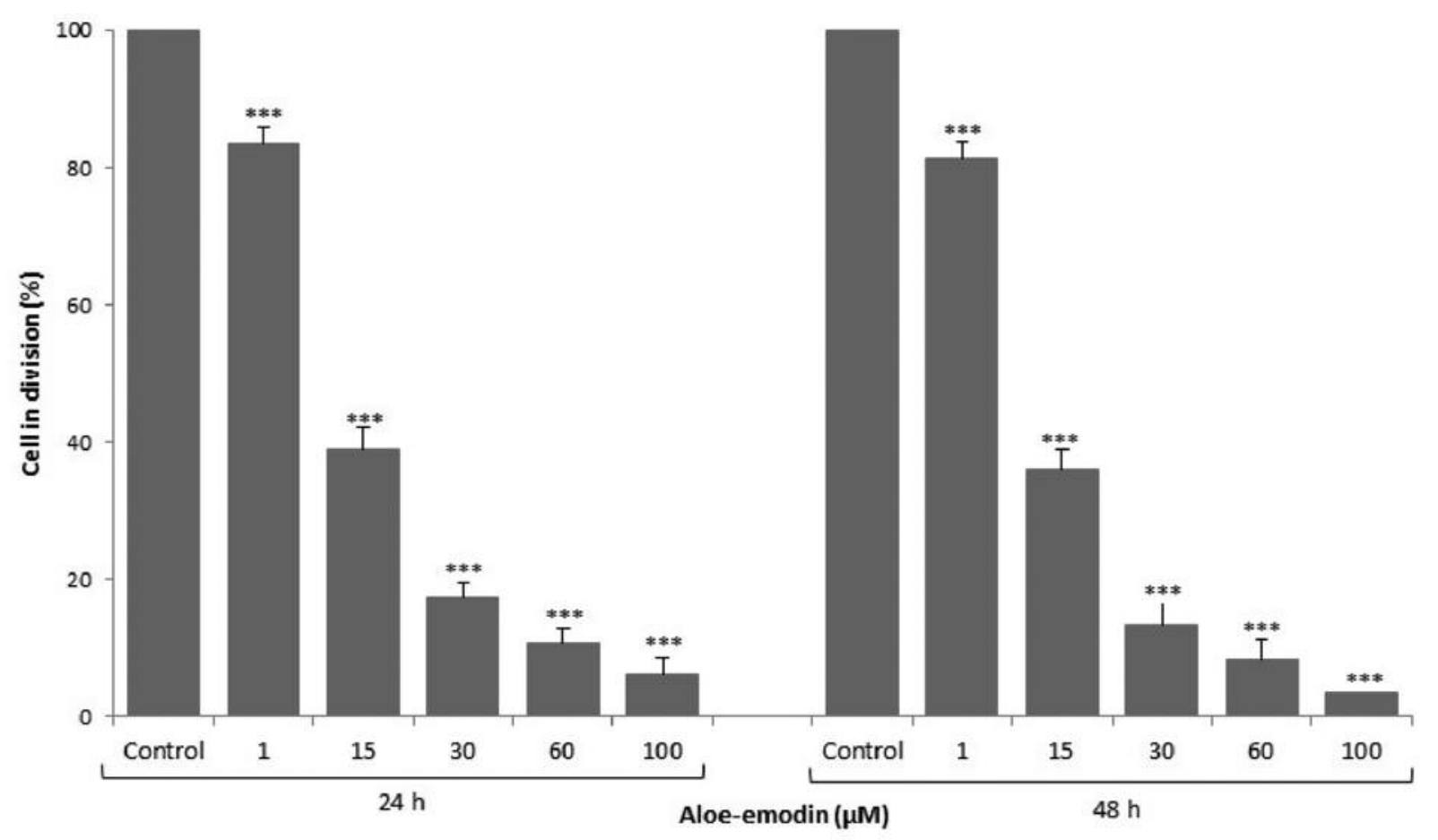

Figure 1. Comparison of the mitotic index of HeLa cells after 24- and 48-hour exposure to different concentrations of aloe-emodin. The results are the average of three repetitions for each group. Differences from the control confirmed statistically at: $* * * p<0.001$.

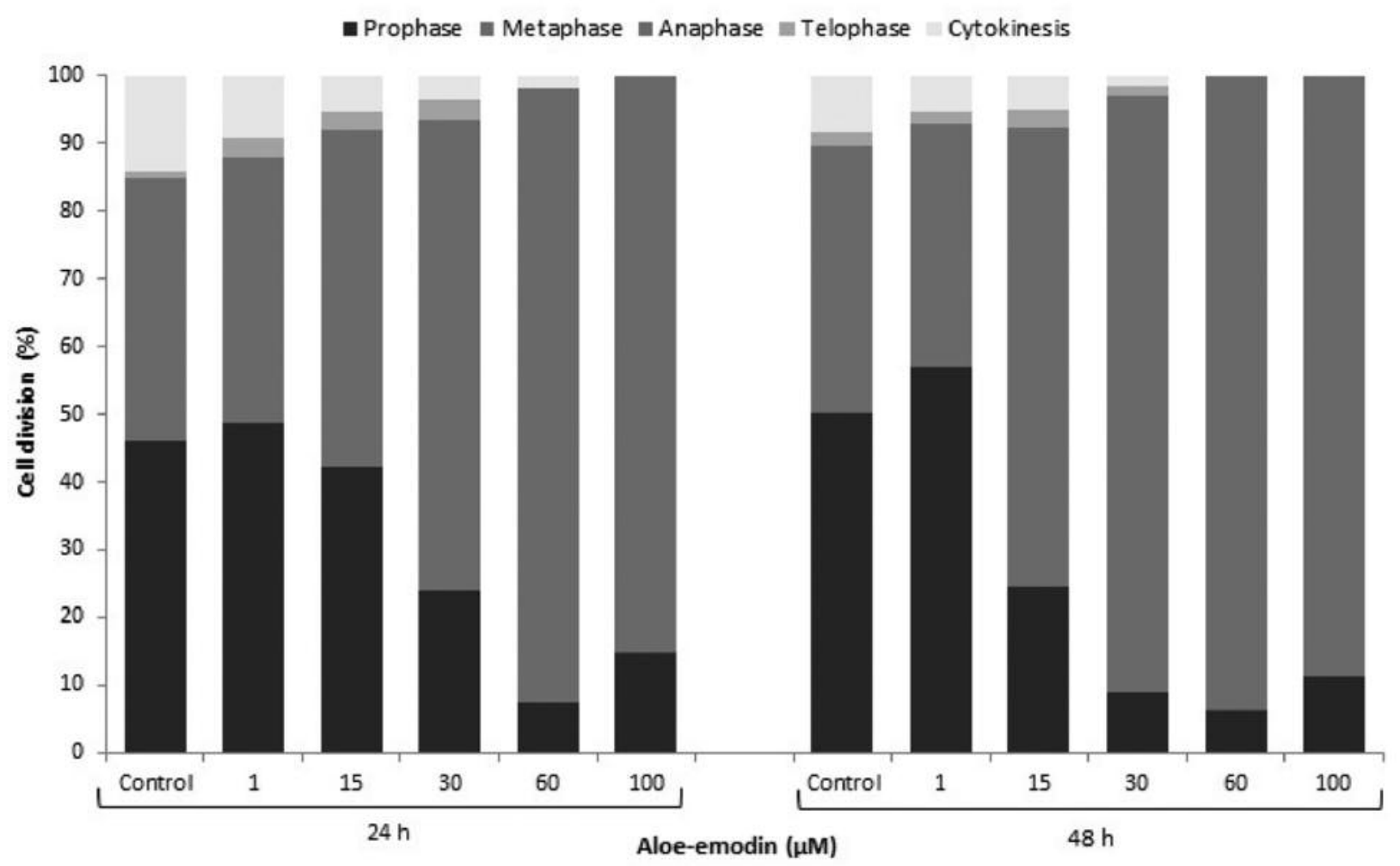

Figure 2. Percentage of mitotic phases of HeLa cell lines after 24-and 48-h exposure to different concentrations of aloe-emodin. 


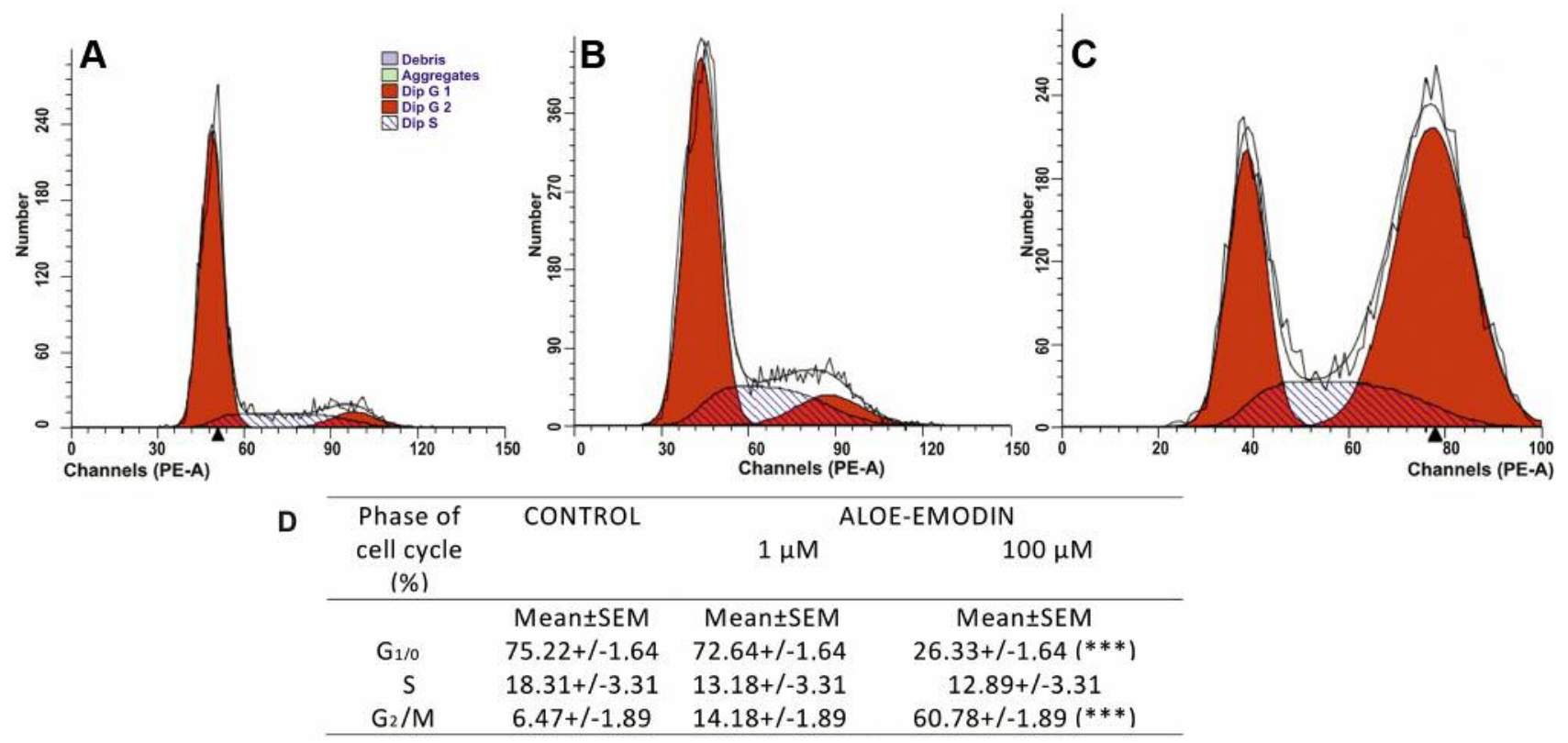

Figure 3. Effect of aloe-emodin on the cell-cycle distribution of HeLa cells. Aloe-emodin increased the proportion of $G_{2} / M$ phase cells and reduced the fraction of $G_{0} / G_{1}$ cells. A: Control cells. B, C: Cells treated for 48 hours with aloe-emodin at a concentration of $1 \mu M(B)$ and at $100 \mu M(C)$. D: Percentage of cells in the individual phases of the cell cycle after treatment with different aloe-emodin concentrations for 48 h. Differences from the control confirmed statistically at: $* * * p<0.001$.

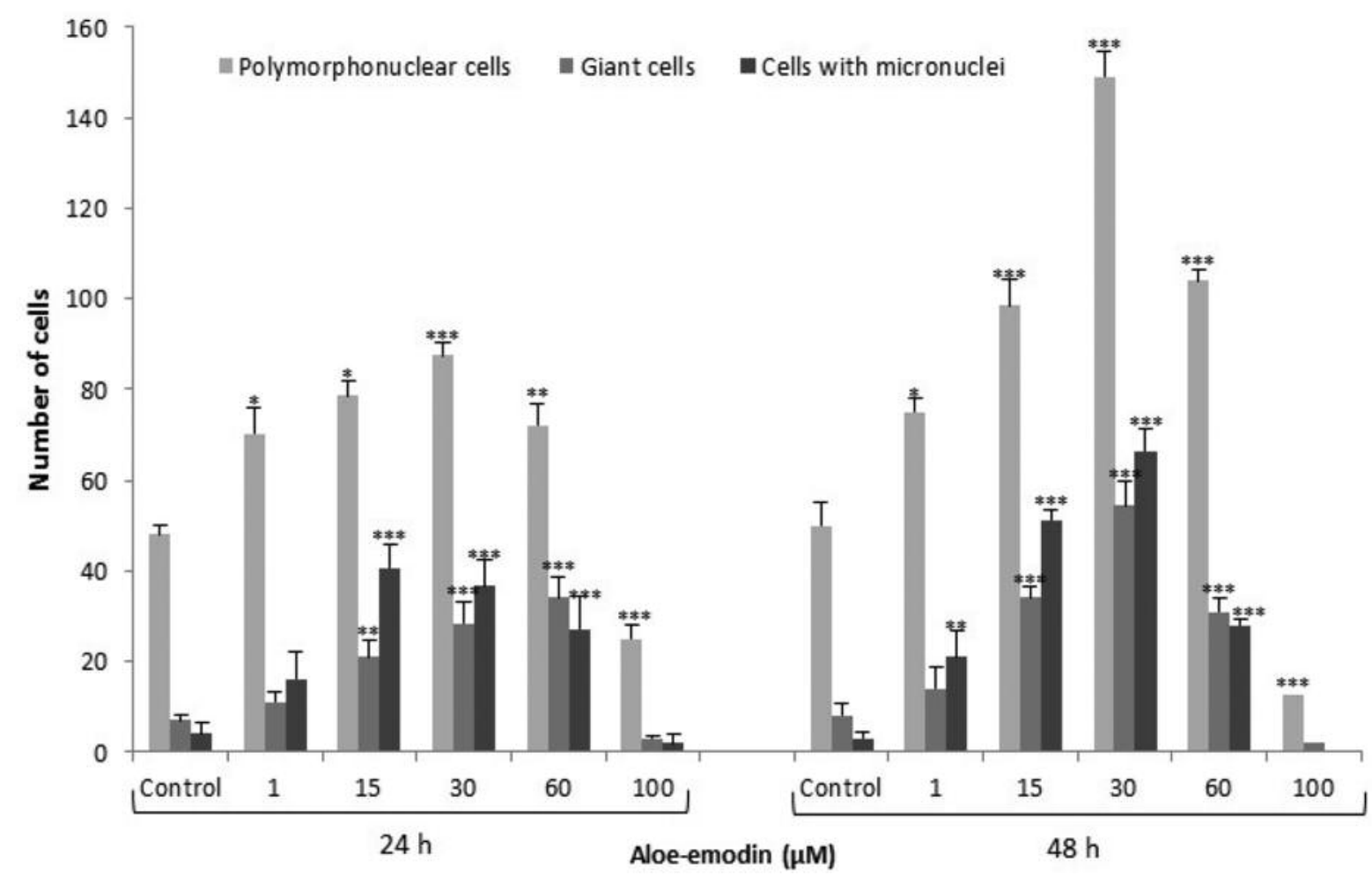

Figure 4. Comparison of the number of multinucleated cells, giant cells and HeLa cells with micronuclei after 24- and 48-hour exposure to different concentrations of aloe-emodin. Differences from the control confirmed statistically at: $* p<0.05, * * p<0.01, * * * p<0.001$. 

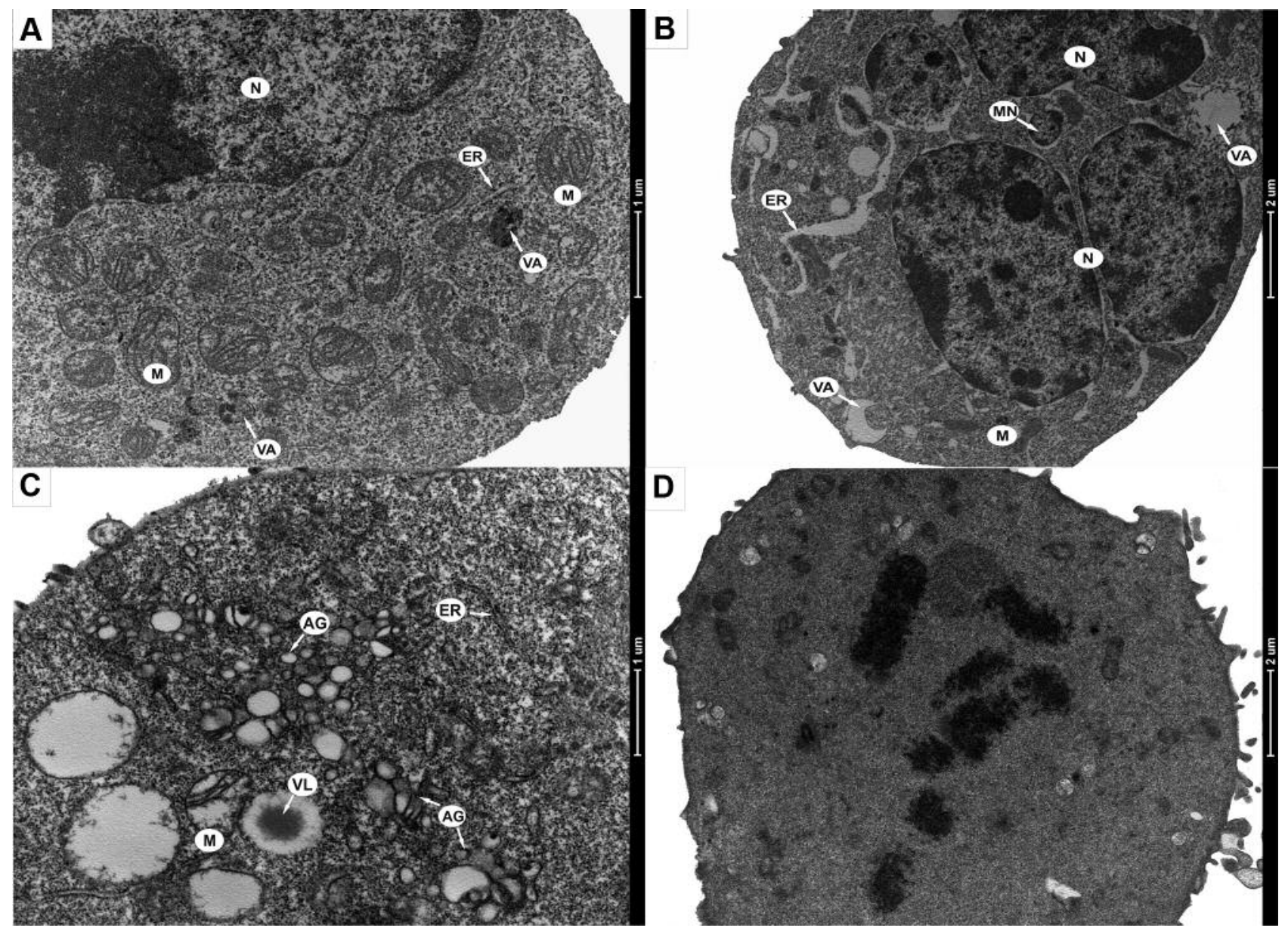

Figure 5. Ultrastructural changes characteristic of mitotic catastrophe in Hela line cells treated for $48 \mathrm{~h}$ with aloe-emodin (AE). A: Control cell, $B$ : giant multinucleated cell $(A E=30 \mu M), C$ : cell with dispersed Golgi cisternae in the cytoplasm $(A E=15 \mu M)$, D: cell undergoing abnormal mitosis with highly condensed nuclear material $(A E=60 \mu M)$. $N$ : Cell nucleus, MN: micronuclei, ER: endoplasmic reticulum, M: mitochondria, VA: autophagic vacolue, VL: lipid vacuole, AG: golgi apparatus. Magnification, ×16,500.

concentration $\left(\mathrm{IC}_{50}\right.$ value) for aloe-emodin was determined by the MTT assay as $66.40 \mu \mathrm{M}$, while the $\mathrm{IC}_{90}$ (concentration inhibiting cell growth by $90 \%$ ) as $75.21 \mu \mathrm{M}$. The highest reduction in cell viability (to $7.30 \%$ ) was found at $100 \mu \mathrm{M}$ aloe-emodin. At the same time, a highly significant increase in the number of apoptotic cells was observed after $24(74.7 \%)$ and $48(78.3 \%)$ hours of exposure to the test compound at $100 \mu \mathrm{M}$ (Figure 7A). Apoptotic cells (labeled with DAPI fluorochrome) were characterized by clear chromatin condensation and nuclear fragmentation (Figure 7C).

\section{Discussion}

Among the existing models of cell death, such as apoptosis, necrosis, autophagy, oncosis, mitotic catastrophe is least described. It is the death of the cell in which anomalies occur during the process of mitosis. Mitotic catastrophe is a consequence of the dysfunction of cell-cycle checkpoints, and consequently improper chromosomal segregation and cell division. Morphologically, it is reflected by fragmentation of the nucleus, and the formation of large cells with one nucleus (13). Characteristic features may also be the lack of a nucleus or the presence of two or more nuclei in the cell, the formation of cells with a micronucleus, multinucleated cells, and giant cells, which are recognized as mitotic death markers (13). Cell death due to mitotic catastrophe occurs during mitosis, or as a result of its arrest in metaphase regardless of p 53 or during abnormal mitotic division depending on p53 $(1,2,14)$.

As a consequence of the 24- and 48-h action of the anthraquinone studied here on HeLa cells, an increase in the number of cells with micronuclei that arise during mitotic cell division was observed. The main mechanism contributing to their formation are chromosomal breakdown and dysfunction of the mitotic apparatus, the effect of which 


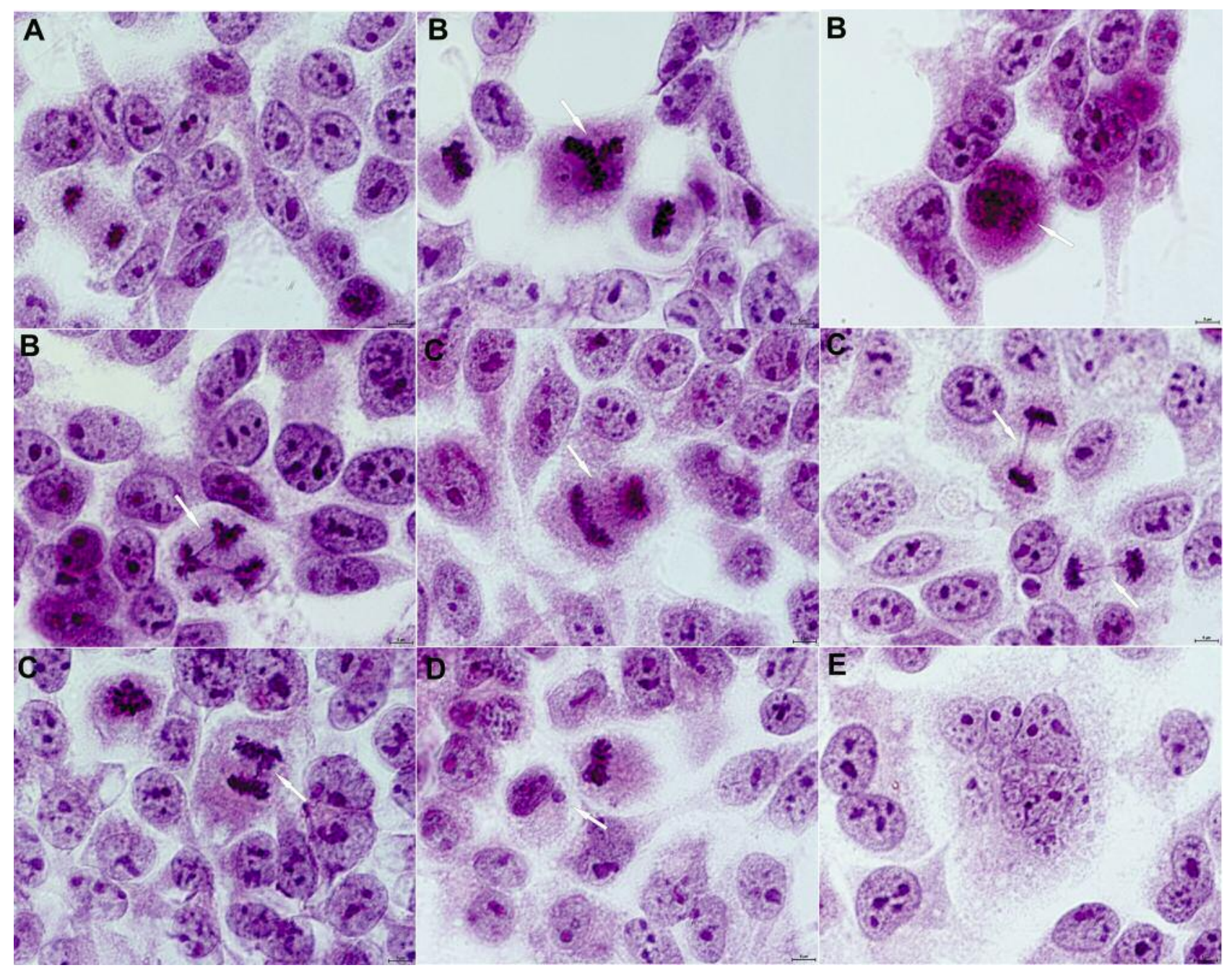

Figure 6. Morphological changes in Hela cell line treated with aloe-emodin for 48 h. A: Control cells (interphase and normal cell divisions), B: cells with abnormal metaphase (bipolar, three: polar, multipolar), C: cells with abnormal chromosomal segregation, D: cell with micronuclei, E: giant polymorphonuclear cell (hematoxylin and eosin). Magnification, x1,000.

is their not being moved to the poles of the dividing cells and staying in the cytoplasm (15).

A statistically significant increase in the population of cells in the $G_{2} / M$ phase of the cell cycle, with simultaneous reduction of cells in the $\mathrm{G}_{0} / \mathrm{G}_{1}$ phase (Figure $3 D$ ), the retention of cell division mainly at the metaphase stage (Figure 2) and the presence of mitotic death markers, i.e. cells with abnormal mitosis (Figure 6), as well as an increase in the number of multinucleated and giant cells (Figure 4), testify to the sensitivity of tumor cells to the effects of aloe-emodin. Numerous literature data indicate that cells undergoing abnormal mitosis may undergo subsequent apoptotic death $(8$, 9). It is also believed that apoptosis may occur during mitotic catastrophe but through caspase-independent pathways (16). The highly statistically significant increase in the number of apoptotic cells revealed in the studies here is shown in Figure 7A and C. Our team's research revealed that aloe-emodin can stimulate the death of HeLa cells during mitosis through the process of mitotic catastrophe (Figure 4B and D, Figure 6).

As can be seen from the available literature, chemotherapeutics that affect the mitotic spindle may be the most effective in killing cancer cells, especially those resistant to apoptosis (16). In these cells, the signaling pathways leading to apoptosis are blocked (17).

It should be noted that the morphological indicators of death mitotic analyzed here were also observed in cells treated with other anticancer compounds, such as vinca alkaloids (vinflunine, vinorelbine, vincristine, vinblastine), taxanes (paclitaxel, docetaxel) (17-23), oxaliplatin (24), cisplatin (25), and doxorubicin (26). 

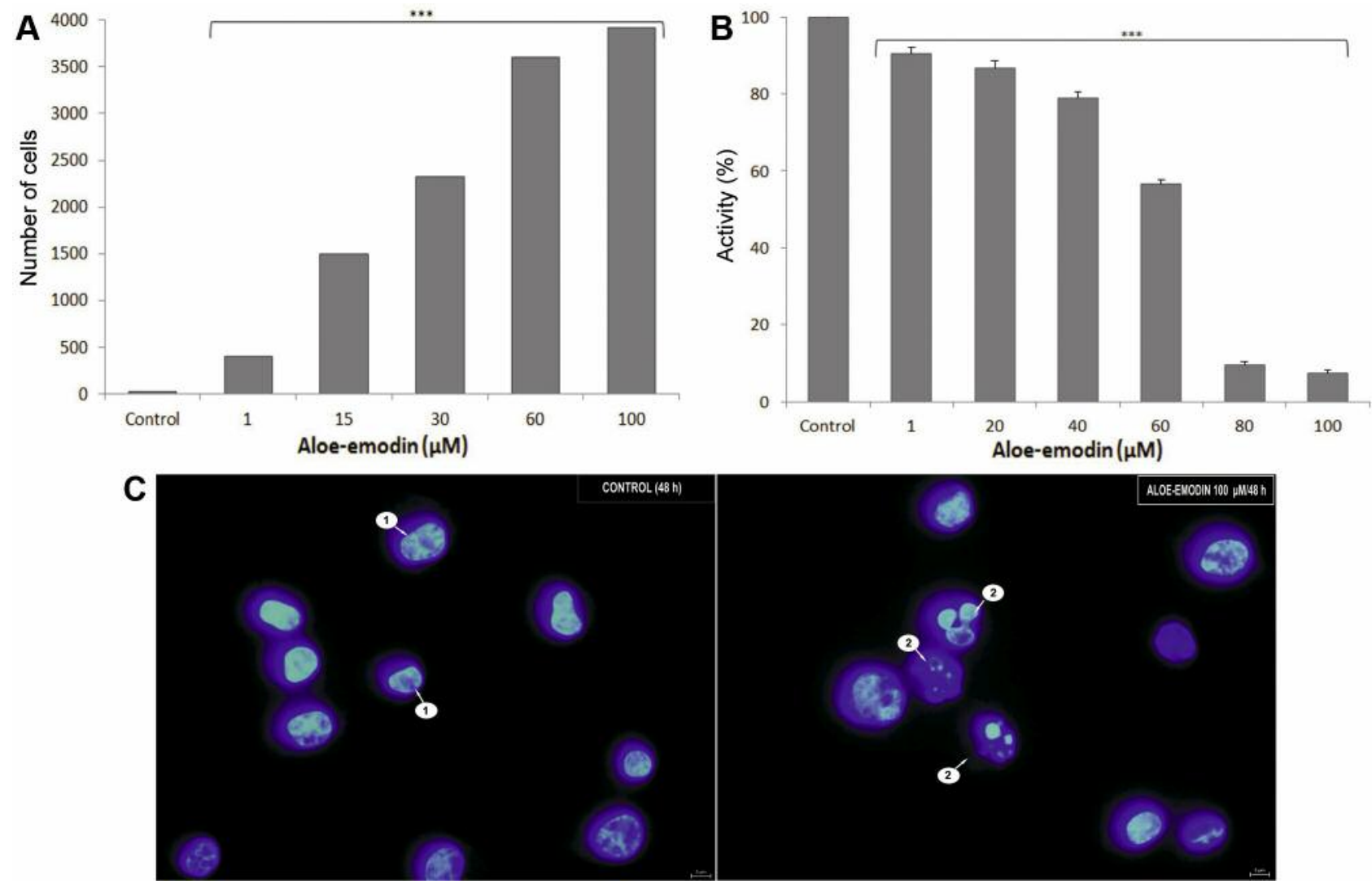

Figure 7. Death of HeLa cell line induced after $48 \mathrm{~h}$ incubation with aloe-emodin at increasing concentrations. A: The number of apoptotic cells increased highly statistically significantly in a concentration-dependent manner. B: Cell viability determined by MTT assay after exposure to different concentrations of aloe-emodin. Differences were confirmed statistically at: $* * * p<0.001$. The half-maximal inhibitory concentration/concentration inhibiting cell growth in $90 \%: 66.401 \pm 0.68 \mu \mathrm{M}$ and $75.216 \pm 0.83 \mu \mathrm{M}$. C: Nuclear morphology in cells incubated with aloe-emodin at a concentration of $100 \mu$ M. 1: Control cell with normal morphology of the nucleus. 2: Apoptotic cell with clear nuclear fragmentation (4',6-diamidine-2-phenylindole staining). Magnification, $\times 600$.

A characteristic morphological change after aloe-emodin is also visible in Figure 4C, the dispersal of the Golgi apparatus. Numerous data indicate that the cytoskeleton plays a key role in the organization of the Golgi apparatus $(27,28)$. The changes revealed (Figure 5C) suggest that aloe-emodin induces disorganization of the cytoskeleton of the cell and at the same time indicates its antiproliferative properties.

Of note is the lack of cells in the anaphase, telophase and cytokinesis stage in cells treated with aloe-emodin at a concentration of $100 \mu \mathrm{M}$, which may additionally indicate its effect on the dividing spindle (Figure 2). Similar morphological changes have been demonstrated in cells treated with antimitotic drugs such as vincristine (29), colchicine $(30,31)$ and taxol $(32,33)$.

As shown in our studies, depending on concentration and exposure time (Figures 5-7), the death of HeLa cells on the path of mitotic catastrophe induced by aloe-emodin can be an alternative to apoptosis. In our research, we also showed that another anthraquinone, emodin, is a compound that promotes the death of cervical cancer cells through mechanism that occurs with involvement of the lysosomal compartment (34).

Aloe-emodin showed a concentration-dependent and timedependent induction of mitotic death in HeLa cell lines. This compound has similar effect to those currently used in the oncological treatment of plant-derived cytostatic. The changes in HeLa cells induced by aloe-emodin indicate its great potential as an anticancer compound.

\section{Conflicts of Interest}

All Authors have read the Journal's policy on disclosure of potential conflicts of interest and have none to declare.

\section{Acknowledgements}

This work was supported by Jan Kochanowski University, grant: 066/R/11 


\section{References}

1 Castedo M, Perfettini JL, Roumier T, Valent A, Raslova H, Yakushijin K, Horne D, Feunteun J, Lenoir G, Medema R, Vainchenker W and Kroemer G: Mitotic catastrophe constitutes a special case of apoptosis whose suppression entails aneuploidy. Oncogene 23: 4362-4370, 2004.

2 Castedo M, Perfettini JL, Roumier T, Andreau K and Kreomer G: Cell death by mitotic catastrophe: a molecular definition. Oncogene 23: 2825-2837, 2004.

3 Zhang LM, Xie WG, Wen TT and Zhao X: Thermal behavior of five free anthraquinones from rhubarb. J Therm Anal Calorim 100: 215-218, 2010.

4 Kovacevic N, Subotic A, Budimir S and Grubišic D: Comparative study of anthraquinones from embryogenic callus tissue and zygotic embryos of Frangula alnus and Rhamnus catharticus. Pharm Biol 38: 321-325, 2000.

5 Choi S and Chung MH: A review on the relationship between aloe vera components and their biologic effects. Semin Integr Med 1: 53-62, 2003.

6 Chiu TH, Lai WW, Hsia TCH, Yang JS, Lai TY, Wu PP, Ma $\mathrm{CHY}$, Yeh CHCH, Ho CHCH, Lu HF, Wood WG and Chung JG: Aloe-emodin induces cell death through S-phase arrest and caspase-dependent pathways in human tongue squamous cancer SCC-4 Cells. Anticancer Res 29: 4503-4512, 2009.

7 Lin SY, Lai WW, Ho ChCh, Yu FS, Chen GW, Yang JS, Liu $\mathrm{KCh}$, Lin ML, Wu PP, Fan MJ and Chung JG: Emodin induces apoptosis of human tongue squamous cancer SCC-4 cells through reactive oxygen species and mitochondria-dependent pathways. Anticancer Res 29: 327-336, 2009.

8 Vitale I, Galluzzi L, Castedo M and Kroemer G: Mitotic catastrophe: a mechanism for avoiding genomic instability. Nat Rev Mol Cell Biol 12: 385-92, 2011.

9 Vakifahmetoglu H, Olsson M and Zhivotovsky B: Death through a tragedy: mitotic catastrophe. Cell Death Differ 15: 1153-1162, 2008.

10 Fenech M: The in vitro micronucleus technique. Mutat Res 455: 81-95, 2000.

11 Marzella L and Glaumann H: Increased degradation In rat liver induced by vinblastine. II. Morphological characterization. Lab Invest 42: 18-27, 1980.

12 Mossmann T: Rapid colorimetric assay for cellular growth and survival: application to proliferation and cytotoxicity assays. J Immunol Meth 65: 55-63, 1983.

13 Okada $\mathrm{H}$ and Mak TW: Pathways of apoptotic and non-apoptotic death in tumour cells. Nat Rev Cancer 4: 592-60, 2004.

14 Portugal J, Mansilla S and Bataller M: Mechanisms of drug-induced mitotic catastrophe in cancer. Curr Pharm Des 16: 69-78, 2010.

15 Fenech M, Kirsch-Volders1 M, Natarajan AT, Surralles J, Crott JW, Parry J, Norppa H, Eastmond DA, Tucker JD and Thomas P: Molecular mechanisms of micronucleus, nucleoplasmic bridge and nuclear bud formation in mammalian and human cells. Mutagenesis 26: 125-132, 2011.

16 Aoki H, Takada Y, Kondo S, Sawaya R, Aggarwal BB and Kondo Y: Evidence that curcumin suppresses the growth of malignant gliomas in vitro and in vivo through induction of autophagy: role of AKT and extracellular signal-regulated kinase signaling pathways. Mol Pharmacol 72: 29-39, 2007.

17 Morse DL, Gray H, Payne CM and Gillies RJ: Docetaxel induces cell death through mitotic catastrophe in human breast cancer cells. Mol Cancer Ther 4: 1495-1504, 2005.
18 Magalska A, Sliwinska M, Szczepanowska J, Salvioli S, Franceschi C, Sikora E: Resistance to apoptosis of HCW-2 cells can be overcome by curcumin- or vincristine-induced mitotic catastrophe. Int J Cancer 119: 1811-1818, 2006.

19 Horbay RO, Kashchak NI, Stoika RS: A comparison of paclitaxel and vinblastine induced giant cell formation in murine nk/ly lymphoma. Studia Biologica 5: 69-76, 2011.

20 Horbay R and Stoika R: Giant cell formation: the way to cell death or cell survival? Cent Eur J Biol 6: 675-684, 2011.

21 Ngan VK, Bellman K, Hill BT, Wilson L and Jordan MA: Mechanism of mitotic block and inhibition of cell proliferation by the semisynthetic vinca alkaloids vinorelbine and its newer derivative vinflunine. Mol Pharmacol 60: 225-232, 2001.

22 Merlin JL, Bour-Dill C, Marchal S, Bastien L and Gramain MP: Resistance to paclitaxel induces time-delayed multinucleation and DNA fragmentation into large fragments in MCF-7 human breast adenocarcinoma cells. Anticancer Drugs 11: 295-302, 2000.

23 Jordan MA, Toso RJ, Thrower D and Wilson L: Mechanism of mitotic block and inhibition of cell proliferation by taxol at low concentrations. Proc Natl Acad Sci Cell Biology 90: 9552-9556, 1993.

24 Ngan ChY, Yamamoto H, Takagi A, Fujie Y, Takemasa I, Ikeda M, Takahashi-Yanaga F, Sasaguri T, Sekimoto M, Matsuura N and Monden M: Oxaliplatin induces mitotic catastrophe and apoptosis in esophageal cancer cells. Cancer Sci 99: 129-139, 2008.

25 Vakifahmetoglu H, Olsson M, Tamm C, Heidari N, Orrenius S and Zhivotovsk B: DNA damage induces two distinct modes of cell death in ovarian carcinomas. Cell Death Differ 15: 555-566, 2008.

26 Mansilla S, Priebe W and Portugal J: Mitotic catastrophe results in cell death by caspase-dependent and caspase-independent mechanisms. Cell Cycle 5: 53-60, 2005.

27 Egea G, Serra-Peinado C, Gavilan MP and Rios RM: Cytoskeleton and golgi-apparatus interactions: a two-way road of function and structure. Cell Health Cytoskelet 7: 37-54, 2015.

28 Thyberg $\mathbf{J}$ and Moskalewski S: Role of microtubules in the organization of the golgi complex. Exp Cell Res 246: 263-279, 1999.

29 Groth-Pedersen L, Ostenfeld MS, Hřyer-Hansen M, Nylandsted $\mathrm{J}$ and Jäättelä M: Vincristine induces dramatic lysosomal changes and sensitizes cancer cells to lysosome-destabilizing siramesine. Cancer Res 67: 2217-25, 2007.

30 Król T: Influence of colchicine on autodegradation in mouse hepatocytes. Acta Biol Cracov ser Zool 40: 31-39, 1998.

31 Pavelka $\mathrm{M}$ and Ellinger A: Effect of colchicine on the golgi complex of rat pancreatic acinar cells. J Cell Biol 97: 737-48, 1983.

32 Król T: Activity of lysosomal system in mouse liver after taxol administration. General Paharmacology 30: 239-243, 1998.

33 Hoshino H, Tamaki A and Yagura T: Process of dispersion and fragmentation of golgi complex by microtubule bundles formed in taxol treated HeLa cells. Cell Struct Funct 22: 325-334, 1997.

34 Trybus W, Król T, Trybus E, Kopacz-Bednarska A, Król G and Karpowicz E: Changes in the lysosomal system of cervical cancer cells induced by emodin action. Anticancer Res 37: 60876096, 2017.

Received January 24, 2018

Revised February 16, 2018

Accepted February 23, 2018 